\title{
Cytotoxicity and reactive oxygen species generation from aggregated carbon and carbonaceous nanoparticulate materials
}

\author{
Kristine M Garza' \\ Karla F Soto ${ }^{2}$ \\ Lawrence E Murr ${ }^{3}$ \\ 'Department of Biological Sciences, \\ The University of Texas at El Paso, \\ El Paso, TX, USA; ${ }^{2}$ Lockheed Martin \\ Aeronautics Company, Forth \\ Worth, TX, USA; ${ }^{3}$ Department \\ of Metallurgical and Materials \\ Engineering, The University of Texas at \\ El Paso, EI Paso, TX, USA
}

\begin{abstract}
We have investigated the cytotoxicity and reactive oxygen species (ROS) generation for indoor and outdoor soots: candle, wood, diesel, tire, and natural gas burner soots - along with surrogate black carbon, various multiwall carbon nanotube aggregate materials, $\mathrm{TiO}_{2}$ (anatase) and chrysotile asbestos as reference materials. All soots were observed utilizing TEM and FESEM to be composed of aggregated, primary spherules (20-80 nm diameter) forming complex, branched fractal structures. These spherules were composed of intercalated, turbostratic arrangements of curved graphene fragments with varying concentrations of polycyclic aromatic hydrocarbon (PAH) isomers. In vitro cultures with an immortalized human lung epithelial carcinoma cell line (A549) treated with these materials showed decreased cell viability and variations in ROS production, with no correlations to PAH content. The data demonstrate that soots are cytotoxic and that cytotoxicity is not related to PAH content but is related to ROS generation, suggesting that soot induces cellular oxidative stress and that cell viability assays can be indicators of ROS production.
\end{abstract}

Keywords: cytotoxicity assessment, ROS assays, FESEM and TEM analysis, nanoparticulate aggregates

\section{Introduction}

Epidemiological, laboratory, and clinical studies have shown that exposure to ambient particulate matter (PM), particularly nano-PM, is associated with adverse health effects (Englert 2004; Pope and Dockery 2006) which include pulmonary and cardiovascular diseases such as chronic obstructive pulmonary disease (COPD) (D'Amato and Liccordi 1998; Johnson 2004; Pope et al 2004); leading to morbidity (Peters et al 1997) and mortality (Pope et al 1995; Samet et al 2000; Pietropaoli et al 2004). Indeed, the relationship between increased ambient air pollution and adverse health effects in individuals with asthma, children (and especially children with asthma), and other vulnerable adults, is well documented (Koenig et al 2005; Nel 2005; Gwinn and Vallyathan 2006; Pope and Dockery 2006). Inhaled or instilled ambient ultrafine or nanoPM induces pulmonary inflammation, oxidative stress, and distal organ involvement in animals (Nel 2005; Oberdörster et al 2005; Donaldson et al 2004; Frampton 2001; Donaldson 2002), and in vitro cell culture analyses support these physiological responses observed (in vivo). This is indicative of the role played by oxidative stress (reactive oxygen species [ROS]) and the production of inflammatory cytokines and other cytotoxic cellular responses resulting from exposure to superoxide, hydrogen peroxide, and hydroxyl radicals (Donaldson and Tran 2002; Bell 2003; Donaldson et al 2004; Shredova et al 2005; Nel et al 2006).

From a fundamental or mechanistic perspective, ROS generation and the induction of oxidative stress seems to be the most plausible paradigm to explain the in vivo 
and in vitro toxic effects of inhaled nano-PM (Bell 2003; Shredova et al 2005; Nel et al 2006). Nano-PM is mostly derived from combustion sources, both indoor and outdoor (Geller et al 2002; Nel et al 2006), and these carbon and/or carbonaceous nano-PM are heterogeneous in size, and often consist of complex, fractal-like aggregates of turbostratic graphene (carbon) curved fragments composing primary PM spherules, or multi-concentric fullerenic and carbon nanotube structures. Carbonaceous PM or soot, exhibits similar, complex, branched aggregates composed of turbostratic, curved graphene fragments intercalated with varying concentrations of polycyclic aromatic hydrocarbon (PAH) isomers having molecular weights (MW) that can range from MW 128 for naphthalene to MW 278 for dibenz[a,h]anthracene, depending upon the specific combustion chemistry, thermodynamics, and kinetic interactions which characterize the source (Homann 1998; Vander Wal and Tomasek 2004; Violi and Venkatnathan 2006). These sources include candle, natural gas, cooking, and wood-burning soot PM indoors, and a host of outdoor soots including diesel, tire, wood, natural gas and other combustion soots as well as various, other mobile and stationary combustion sources (including automobiles, trucks, and trains) and soots associated with agricultural burning, etc. These carbon and carbonaceous nano-PM aggregates also include or consist of various designations of so-called elemental carbon (EC) and black carbon (BC), which is also contributed from vehicular tire wear (Dahl et al 2006), since tire compositions include $\sim 30 \% \mathrm{BC}$.

Elemental carbon specifically has been associated with respiratory health effects in children (Gauderman et al 2004), and in a recent study by Kim and colleagues (2004) concentrations of traffic-related PM, particularly BC, were associated with respiratory symptoms in children. Black carbon increases were associated with a decrease in flow-mediated vascular reactivity in elderly subjects as well (O’Neili et al 2005). Chalupa and colleagues (2004) have shown that the total number of nano-PM retained in the lungs was 74\% greater in subjects with asthma than in healthy subjects, and "that people with asthma have a higher total respiratory dose of nano-PM (or ultrafine particulates) for a given exposure, which may contribute to their increased susceptibility to the health effects of air pollution." Deposition of ultrafine particulates increased with exercise in asthma subjects along with increased minute ventilation and hyperinflation even in mild asthma cases, characteristic of diffusional deposition of ultrafine particulates in the distal airways and alveoli.

While oxygen is essential for life, the formation of partially reduced (or reactive) oxygen species (ROS) imposes a threat to cells. Normal cellular homeostasis therefore involves a delicate balance between the rate and amount of ROS production and the rate of oxidant elimination. Oxidative stress can be defined as the pathogenic outcome of the over production of ROS that overwhelms the cellular antioxidant capacity. ROS are normally cleared from the cell by the action of superoxide dismutase (SOD), catalase, or glutathione (GSH) peroxidase (Hellawell and Gutteridge 1999), but over production damages cells by the alteration of macromolecules such as polyunsaturated fatty acids in membrane lipids, protein denaturation, and ultimately DNA.

In this study we have undertaken a detailed electron microscope characterization of the physical nanostructures of carbon and carbonaceous nano-PM as discussed above, along with in vitro assays for ROS production and cytotoxicity as evidenced by relative cell viability or cell death in order to begin to establish a simple predictive paradigm for toxicity screening and respiratory insult potential. We have utilized data from several prior studies to provide a broader overview of the cytotoxic response and have noted the specific sources where appropriate.

\section{Materials and methods Nanoparticulate aggregate characterization}

This study was concerned with the collection, characterization, and in vitro analyses of various, specific carbon nanoparticulates (multiwall carbon nanotube aggregates, including commercially manufactured surrogate materials), black carbon (BC), and a variety of soot nano-PM: derived from tire, wood, and candle burning, diesel PM, and various natural gas combustion nano-PM. In addition, we utilized chrysotile asbestos and $\mathrm{TiO}_{2}$ (anatase) as reference (positive control) nano-PM.

We examined the nano and microstructures as well as the crystallinity and crystal-structure details of all of the nanoparticulate materials tested using a variety of collection substrates amenable to either scanning electron microscopy, transmission electron microscopy, or both. The manufactured nanoparticulate materials were placed between silicon monoxide/formvar-coated 200 mesh $\mathrm{Ni}$ grids for observation in the TEM. Carbonaceous (soot) nanoparticulates were either collected upon these grids using thermophoretic precipitation (Bang et al 2003; Murr and Bang 2003) for TEM analysis, scraped from filter collections onto the coated grid (sandwiches) for TEM, or observed directly on collection filters (either Ir sputtercoated or uncoated) in the SEM (Murr 1991; Shi et al 2007). The SEM was a Hitachi S-4800 field-emission (FE) 
instrument. Samples were normally observed at low voltage in the FESEM to avoid charging and enhance resolution, either coated with $\sim 4 \mathrm{~nm}$ Ir, or uncoated; in the secondaryelectron emission mode. Uncoated samples were also observed in the STEM mode in the FESEM as well, usually at $20 \mathrm{kV}$ accelerating potential. The TEM utilized was a Hitachi H-8000 analytical TEM operated at $200 \mathrm{kV}$ and employing a goniometer-tilt stage. Bright and dark-field imaging was performed along with selected-area electron diffraction (SAED) analysis and in some cases samples were examined by energy-dispersive X-ray spectrometry (EDS).

\section{Viability (cell death) assays}

Recently we have compared viability assays for a range of nanoparticulate materials for a murine macrophage cell line (RAW 264.7), a human alveolar macrophage cell line (THB-1), and a human general epithelial (cancer) cell line (A549). This is a lung carcinoma cell line which has been used extensively as a human lung cell model. The data indicate that these cell lines each represent similar cell viabilities (or cell death data) in the presence of the nanocarbon material relative to controls, calculated by absorbance of formazan from MTT at $570 \mathrm{~nm}$, for exposure times ranging from $48 \mathrm{~h}$ ( 2 days) to 336 h (2 weeks) (Murr et al 2007; Soto et al 2006, 2007). While it is certainly difficult to prove this similarity using dye-based assays, the corresponding trends provide at least a qualitative representation. We have also developed a new assay for measuring the relative viability for human lung (A549) cells in culture exposed to a wide range of carbonaceous (soot) nanoparticulate materials, including candle soot or candle particulate matter (CPM), diesel particulate matter (DPM), wood particulate matter (WPM), tire particulate matter (TPM), and a variety of kitchen (natural gas) burner combustion nanoparticulates; which can include aggregates of multiwall carbon nanotubes and other multiconcentric fullerenes (Murr et al 2004, 2007; Shi et al 2007). These soot nanoparticulate materials were collected on high-volume air-flow glass fiber filters, which were placed in contact with the human lung cells (A549) in large flat-well arrays (Murr et al 2007; Shi et al 2007). In the present study, we utilized these same nanoparticulate materials (both manufactured and anthropogenic/combustion-generated) to provide a broad comparative assessment of cytotoxicity and the production of ROS, in the widely used in vitro lung model (A549) cells (Frampton 2001; Veronesi et al 2002).

We used the A549 human epithelial cell line cultured in 6-well flat bottom plates $\left(10^{6}\right.$ cells/well $)$, in Kaighn's modification of HAM's F-12 medium (F-12K) with $2 \mathrm{mM}$ L-glutamine containing $1.5 \mathrm{~g} / \mathrm{L}$ sodium bicarbonate, $10 \%$ fetal calf serum $(\mathrm{FCS}), 5 \times 10^{5} \mathrm{M}$ beta-z mercaptoethanol, 100 units $/ \mathrm{mL}$ penicillin $/ 100 \mu \mathrm{g} / \mathrm{mL}$ streptomycin formulated for use with $5 \% \mathrm{CO}_{2}$ at $37^{\circ} \mathrm{C}$. Filters containing collected soot PM were cut into $3.81 \mathrm{~cm}$ diameter circles, autoclaved for $1 \mathrm{~h}$, and placed upside down in the wells, with the collected PM in contact with cells adhering to the well bottom. As controls, the cells remained untreated (media only) or were given the vehicle control (dimethyl sulfoxide DMSO). While DMSO reacts with hydroxyl radicals to produce methyl radicals, we have previously shown that DMSO concentrations up to $35 \mathrm{nM}$ did not inhibit ROS formation (Soto et al 2007). DMSO concentrations used in this study did not exceed $35 \mathrm{nM}$. After $48 \mathrm{~h}$ of incubation (nonagitated), the filters were removed and the cells were then scraped from the wells, and together with their supernatants were transferred to conical tubes. From this sample $100 \mu \mathrm{L}$ was then placed on the standard 96-well plate and $10 \mu \mathrm{L}$ MTT (3-C4,-dimethylthiazol-2-yl)-2, 5-diphenyltetrazolium) $\left(5 \mu \mathrm{g} / \mathrm{mL}\right.$ in $\left.\mathrm{H}_{2} \mathrm{O}\right)$ (Sigma-Aldrich Co, St Louis, MO) was added; the cells were incubated for an additional $6 \mathrm{~h}$; after which $80 \mu \mathrm{L}$ of supernatant was removed and $50 \mu \mathrm{L}$ of lysis buffer (containing $10 \mathrm{~N} \mathrm{HCl}$ in isopropanol) was added and cell viabilities calculated by absorbance of formazan from MTT at $570 \mathrm{~nm}$.

The cells were treated with manufactured nanomaterials diluted in DMSO in 96-well plates. The nanomaterials included: commercial black carbon (BC), an arc evaporationgrown multiwall carbon nanotube aggregate material (MWCNT-R), A Ni-catalyst-grown multiwall carbon nanotube material (MWCNT-N), $\mathrm{TiO}_{2}$ (anatase form), and mineral (chrysotile) asbestos $\left(\mathrm{Mg}_{3} \mathrm{Si}_{2} \mathrm{O}_{5}(\mathrm{OH})_{4}\right)$. The cells were treated with $5 \mu \mathrm{g} / \mathrm{mL}$ of these respective materials for $48 \mathrm{~h}$. Following the treatment period, all media was removed, the cells were trypsinized ( $0.250 \%$ trypsin $)$, and were resuspended in a $3 \%$ protein-containing PBS buffer. The time in PBS was minimal only as a washing step. The cells were then treated with Sytox $(10 \mathrm{nM})$ for $20 \mathrm{~min}$ at $37^{\circ} \mathrm{C}$. Afterwards, the cells were analyzed by flow cytometry (FC500 flow cytometer by Beckman Coulter). To determine the percentage of Sytoxpositive cells, ie, those exhibiting cell death, a total of 10,000 events were assessed per sample using the CXP Software. After $48 \mathrm{~h}$ after incubation in 96-well plate arrays, media was removed, trypsinized, and resuspended in medium before addition of Sytox $(10 \mathrm{nM})$ for 20 minutes at $37^{\circ} \mathrm{C}$. The cells were then analyzed using fluorescence-activated cell sorter (FACS) to determine the percentage of Sytox-positive cells, ie, those exhibiting cell death. 


\section{ROS analysis}

We examined the production of ROS by growing the A549 cells in 96 -well, flat-bottomed plates (50,000 cells per well) in the presence or absence of the nanocarbon materials (along with a DMSO vehicle control). Following a $48 \mathrm{~h}$ incubation, media was removed, the cells were washed with PBS, and were loaded with $10 \mu \mathrm{M}$ DCF-DA (2,7-dichlorofluorescein diacetate) in PBS containing $25 \mathrm{mM}$ HEPES, for $30 \mathrm{~min}$. at $37{ }^{\circ} \mathrm{C}$. DCF-DA is a cell-permeant indictor for reactive oxygen species that is nonfluorescent until the acetate groups are removed by intracellular esterases and oxidation occurs within the cell. The cells were then washed twice and fluorescence intensity was determined at $485 \mathrm{~nm}$ excitation and $590 \mathrm{~nm}$ emission, using an automated fluorescence reader (Fluorocount, Hewlett-Packard Instrument, IL). Cultures in media and DMSO were included and $600 \mu \mathrm{M} \mathrm{H}_{2} \mathrm{O}_{2}$ was added to serve as an ROS reference for the media.

\section{Results and discussion Examples of aggregated nanoparticulate materials microstructures}

Figures 1a and b compare TEM images of aggregated chrysotile asbestos and multiwall carbon nanotube (MWCNT) and multi-concentric fullerenic particles collected by thermophoretic precipitation (Bang et al 2003; Murr and Bang 2003) near a kitchen natural gas (blue flame) burner. The corresponding arrows in Figures 1a and b draw attention to the microstructural, nanotube similarities, including capping of the respective nanotubes, as described in detail by Murr and Soto (2004); in spite of the differences in chemistry $\left(\mathrm{Mg}_{3} \mathrm{Si}_{2} \mathrm{O}_{5}(\mathrm{OH})_{4}\right.$ for asbestos versus $\mathrm{C}$ for the MWCNTs) and the associated wall structure for the chrysotile asbestos nanotubes (Murr et al 2007). Unlike the aggregation of MWCNTs, chrysotile asbestos is only weakly (electrostatically) aggregated, and individual fibers are common in the environment; ranging from short fibers with aspect ratios (length/diameter) of $\sim 3$ to very long fibers with ratios as large as 30,000. Figure 2 shows for comparison with Figure $1 \mathrm{~b}$ typical MWCNT and multi-concentric, fullerenic nanoparticle aggregation for commercial (arc-evaporation-produced) material which is considered to represent a surrogate for anthropogenic MWCNT aggregate material (shown typically in Figure 1b).

In contrast to the regular microstructural nano-forms illustrated in Figures 1 and 2, Figure 3 shows a range of images for burning tire soot which, as illustrated in the TEM image of Figure 3a, consists of complex, branched aggregates of

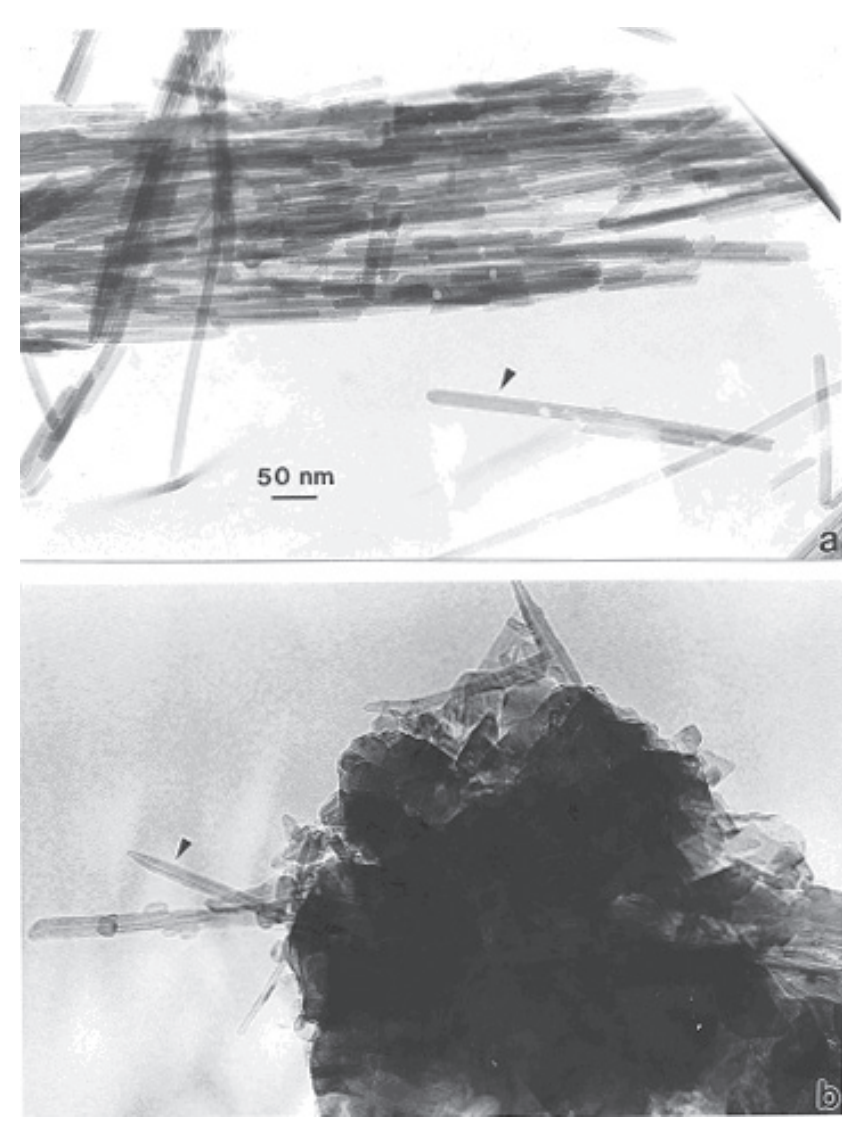

Figure I TEM images comparing chrysotile asbestos aggregate (a) with a MWCNT aggregate collected above a natural gas kitchen burner (b). The arrows in (a) and (b) illustrate the essentially identical nanotube structure and dimensions.

primary nanospherules of turbostratic graphene intercalated with polycyclic aromatic hydrocarbon (PAH) isomers (Murr et al 2007); ranging in diameter from $30 \mathrm{~nm}$ to $60 \mathrm{~nm}$. Figures $3 \mathrm{~b}$ and $\mathrm{c}$ show corresponding STEM and secondary electron (SE) images (Murr 1991) respectively of this aggregated nanomaterial observed in the FESEM. The selected-area electron diffraction (SAED) pattern (Murr 1991) insert in Figure 3a represents the essentially "amorphous" nature of the turbostratic, intercalated graphene and PAH fragment microstructure composing the primary nanospherules. Similar aggregated nanostructures are observed for other soots as illustrated in Figures 4 and 5 which show typical filtercollected wood soots (for an area burning Montana larch and Douglas fir) (Figure 4) and candle soot collected by thermal precipitation (Bang et al 2003; Murr and Bang 2003) and compared with a typical, kitchen cooking soot fragment in Figure $5 \mathrm{~b}$. While the primary spherule structure and dimensions are similar in Figures 3 to 5 a, the overall aggregate structure becomes more compact or spatially dense. This similarity is apparent on comparing the SAED pattern inserts in Figures 3a and 4a, although the more diffuse nature of the 


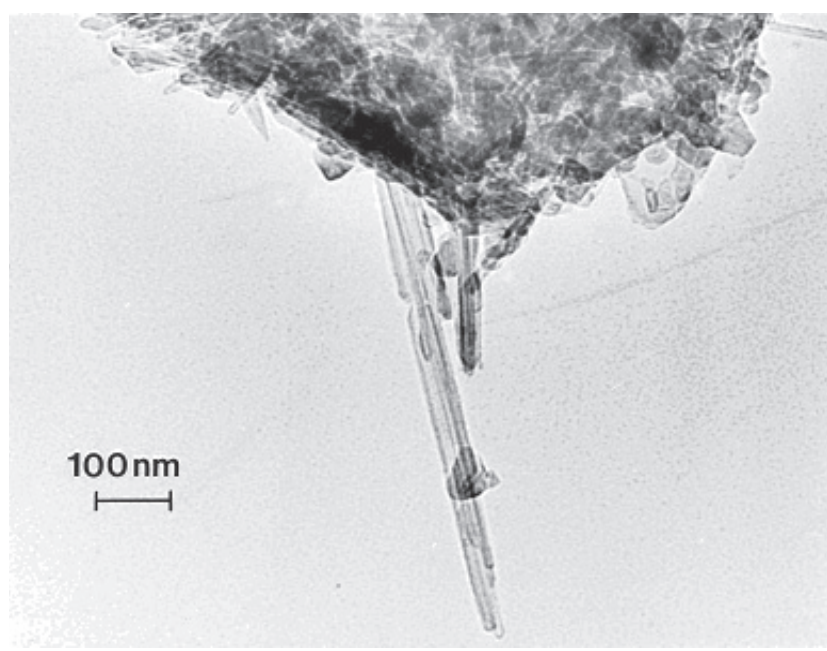

Figure 2TEM image of commercial, arc-evaporation-produced MWCNT-R aggregate material for comparison with Figure I.

SAED pattern in Figure 4a suggests a more turbostratic structure than for the tire soot in Figure 3a. In addition, some wood soots have been observed to contain aggregated MWCNTs (Murr and Guerrero 2006). Commercial black carbon (BC) and diesel soot PM is essentially the same in appearance to those nano-soot aggregates shown for wood and candle PM in Figures 4 and 5a (Murr et al 2007; Shi et al 2007; Soto et al 2007, 2008), although there is a notable variation in PAH content, which has been compared in detail by Shi and colleagues (2007) for the range of carbon and carbonaceous nanoparticulates studied herein.

\section{Viability assays}

Figure 6 shows combined viability assay results for the array of carbon and carbonaceous aggregated nanoparticulates examined in this study and in previous studies (Murr et al 2007; Soto et al 2007, 2008). The notable feature of this comparative data is the comparable cell death response (reduced relative cell viability) for asbestos (chrysotile), commercial $\mathrm{BC}$ and MWCNT aggregate material, and conventional, blue flame, natural gas combustion soot containing variations in MWCNTs aggregated with turbostratic graphene spherule aggregates. The "yellow flame" soot noted in Figure 6 represents lean burning or oxygen-starved (low air flow) natural gas combustion which produces primarily soot represented by Figures 4 and 5a. Although the cytotoxicity results represented in Figure 6 appear to demonstrate a ranking of toxicity for the nanoparticulate aggregates in short-time $(48 \mathrm{~h})$ assays, there is no real quantitative significance to be drawn. It is also to be noted that the nanoparticulate materials on the glass fiber filters varied according to collection times and concentrations (Murr et al 2007). It is, however notable that there is little cytotoxic response for the $\mathrm{TiO}_{2}$ (anatase) nanoparticulate-aggregate material which has been previously demonstrated to exhibit both in vitro and in vivo toxicity variations (Donaldson et al 2001; Oberdöster 2001; Warheit 2004; Soto et al 2005, 2006). Similar toxicity variations for MWCNTs and aggregated single-wall carbon nanotubes have also been discussed recently by Lam and colleagues (2006).

\section{ROS production}

Figure 7 illustrates several representative ROS production assays for the range of nanoparticulate aggregate materials illustrated in Figure 6. There is a notable scale change between the asbestos and BC in Figure 7 (top), and the tire PM and natural gas blue flame PM (Blue) in Figure 7 (bottom). The $\mathrm{BC}$ response in Figure 7 is the most dramatic in terms of ROS production relative to the $\mathrm{H}_{2} \mathrm{O}_{2}$ reference, while
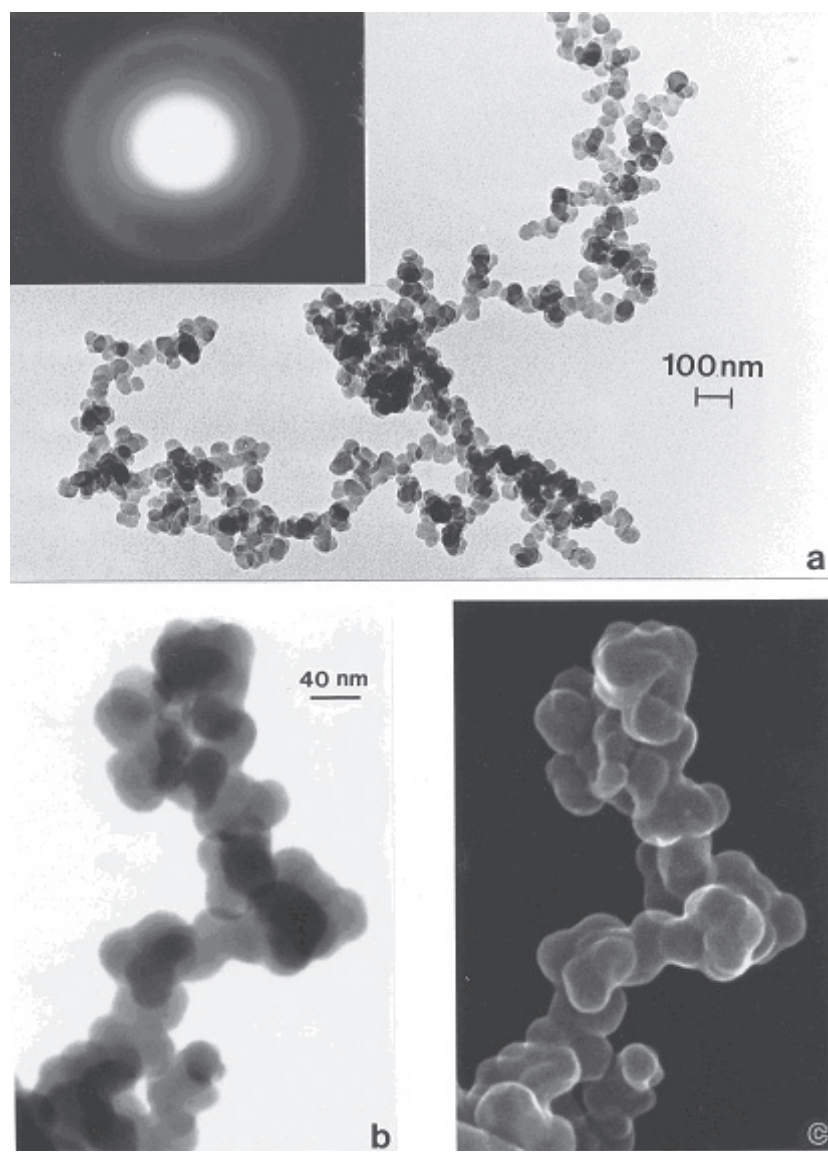

Figure 3 Examples of tire soot nanostructure. (a) TEM image and SAED pattern insert for a portion of a large fractal-like aggregate collected by thermal precipitation (Bang et al 2003) on a SiO/formvar-coated grid. (b) STEM image of an aggregate segment observed in the FESEM at $20 \mathrm{kV}$ accelerating potential. (c) Corresponding SEM image of (b). 

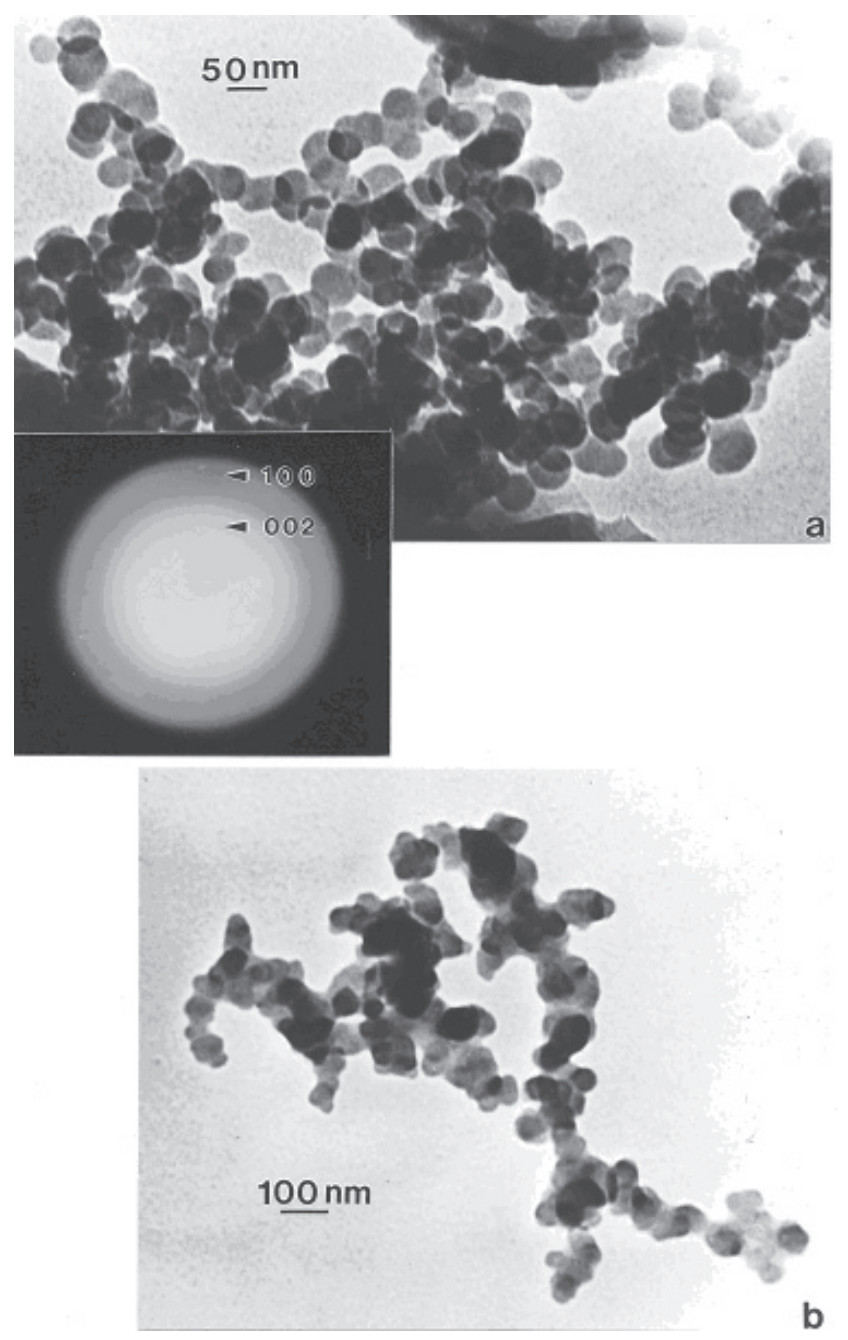

Figure 4 Wood soot examples observed in the TEM (burning douglas fir and larch PM collected on filters and scraped off onto TEM grid sandwich). (a) Large, dense aggregate with superimposed SAED pattern illustrating prominent, (but diffuse) graphite reflections. (b) smaller, fractal-like aggregate.

ROS production for the natural gas blue flame is comparable to that for tire soot, indicative of the fact that indoor soot production in kitchen cooking environments may be as efficient in contributing to oxidative stress as outdoor environments where tire burning may occur.

Figure 8 summarizes and compares the relative ROS production for the experimental nanoparticulate aggregates in contrast to the corresponding, total PAH contents measured in the previous study by Shi and colleagues (2007). It is observed that there is some correlation between relative cell viability (or cell death) shown comparatively in Figure 6 with the relative ROS production shown comparatively in Figure 8, but there is no correlation with ROS production and PAH content. Similarly, Murr and colleagues (2007) have previously demonstrated no correlation with total PAH content (in $\mathrm{mg} / \mathrm{g}$ ) of soots and their cytotoxicity as measured by relative cell viability assays (Figure 6). Consequently, the results suggest that since a correlation exists between ROS production and relative cell viability (or cell death), certain soot PM, especially natural gas combustion PM and soots emulating $\mathrm{BC}$, may induce oxidative stress, especially in indoor environments.

Tables 1 and 2 compare general contents of specific PAHs for the range of nanoparticulate soot aggregates, BC, and MWCNT-R materials examined herein; along with comparative data for PAH content in the indoor air for samplings in S.E. Chicago homes (Van Winkle and Scheff 2001), and homes in El Paso, Texas (Mora et al 2006), where the dominant PAH is observed to be low molecular weight (MW) naphthalene; with smaller amounts of ascending MW to phenanthrene, and traces of pyrene. Aside from candle burning, there are no logical, indoor PM sources of naphthalene (Table 1), except of course the wide range of cooking-related soots. Wood burning and natural gas combustion (either from cooking or from other combustion sources such as hot water heaters and heating systems) may contribute to the lower MW PAHs. While there will be some ingress of outdoor air and associated PM, the PAH data in Table 2 would suggest relatively low concentrations of efficient ROS producing PM indoors, except of course during cooking where kitchen PM mass concentrations can reach levels of 1 to $2 \mathrm{mg} / \mathrm{m}^{3}$ (Lighty et al 2000; Mora et al 2006), or 1000 times the EPA indoor PM standard of $150 \mu \mathrm{g} / \mathrm{m}^{3}$ (Lighty et al 2000). Of course cigarette smoking can contribute to the indoor PM and PAH concentration, as well as the promotion of oxidative stress.

The data in Figure 8 and Tables 1 and 2 do not provide any clear indication of the kinds of nano-PM (especially carbon or carbonaceous, aggregated PM) which may be associated with respiratory ailments derived from indoor environments, including asthma induction or exacerbation. While El Paso is ranked 6th in the U.S. for asthma incidence, recent surveys have indicated that documented and undocumented asthma may be as high as 34 per cent of the population (Murr et al 2006).

The production of ROS by nano-PM such as BC, MWCNTs and natural gas combustion soots in particular (Figure 8) is not connected with PAH content or their MW, but PAHs in the sunlight (outdoors) will be photoexcited, creating a variety of hydroxyl or peroxidase-related ROS, or photo oxidized to quinones which, as illustrated by Nel and colleagues (2006), can contribute to ROS production.

Figure 9, however, illustrates at least a qualitative correlation of ROS production with cell death (or cell viability). 


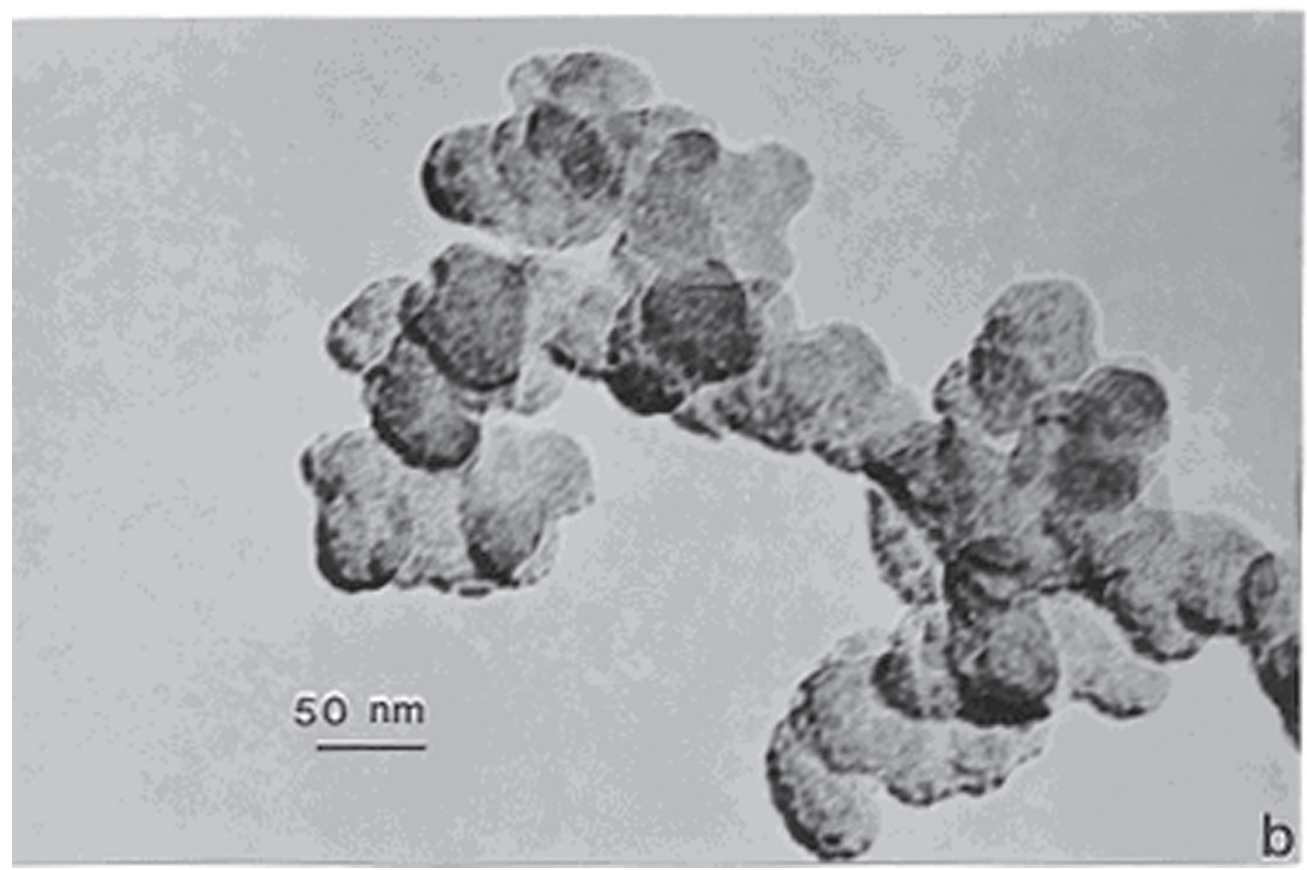

Figure 5 TEM images of soot aggregates collected by thermal precipitation in homes. (a) Candle soot. (b) Unknown soot PM collected in a kitchen.

Cell death in Figure 9 was determined by assuming the relative cell viability for the media in Figure 6 to represent $100 \%$ (or unity). Consequently by dividing the cell viability for each nanoparticulate material by that for the media in Figure 6 and subtracting from unity (or 100\%) produced a semi-quantitative representation for cell death resulting from $48 \mathrm{~h}$ exposure to the specific nanoparticulate material; including the blank fiber glass filter material. Similarly, the relative ROS production was determined using the fluorimeter units measurement for $\mathrm{H}_{2} \mathrm{O}_{2}$ at the maximum time (or time points) in Figure 7, and dividing this into the corresponding fluorimeter units for each nanoparticulate 


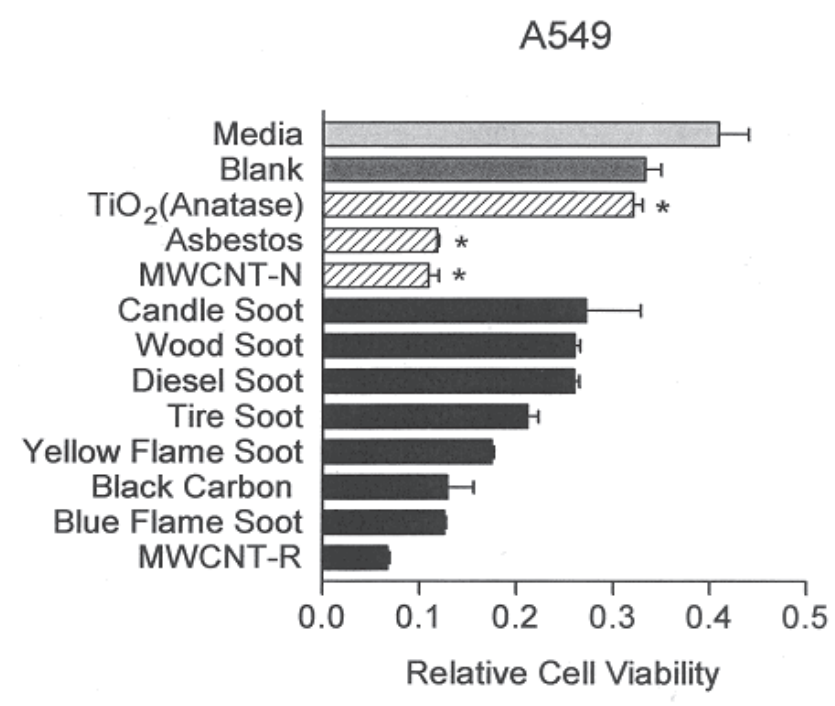

Figure 6 Direct contact, filter-collected soot PM aggregate and surrogate BC and MWCNT $48 \mathrm{~h}$ assays [36] compared with conventional cytotoxicity assay data $(*)$. Data from Soto and colleagues $(2006,2007)$. The relative cell viability at $48 \mathrm{~h}$ for A549 human epithelial (cancer) cell cultures was ascertained for filter-collected soot and for indicated materials at $5 \mu \mathrm{g} / \mathrm{ml}$. The "blank" is a blank reference filter in culture. Yellow flame and blue flame soot refer to rich (oxygen depleted) natural gas combustion and efficient natural gas combustion. Data are presented as the mean \pm SEM of duplicate wells and are one of three representative experiments. material; including the media and the blank fiber glass filter material along with additional fluorimeter data for the other nanoparticulate materials from Soto and colleagues (2008). This is plotted for comparison in Figure 9 for a maximum scale of 10 . Significant ROS production is noted for values $>1$. If an interpolated curve is drawn through the ROS data in Figure 9, it is observed that this curve follows a similar curve for cell death, suggesting that at least qualitatively cell viability assays may provide some corresponding indication of ROS production for nanoparticulate materials.

Figure 9 illustrates a generally higher ROS production and cell death in cytotoxicity assays for soot nanoparticulates, which are variously complex, often fractal-like aggregates of clustered, branches of primary soot nanoparticles with diameters ranging from about $20 \mathrm{~nm}$ to $80 \mathrm{~nm}$. It has been shown that specific surface area is not related to cytotoxic responses especially for soot nanoparticulate aggregates (Soto et al 2007), and Warheit and colleagues (2006) have drawn the same conclusion for other nanoparticulate materials. Nel and colleagues (2006) have included in
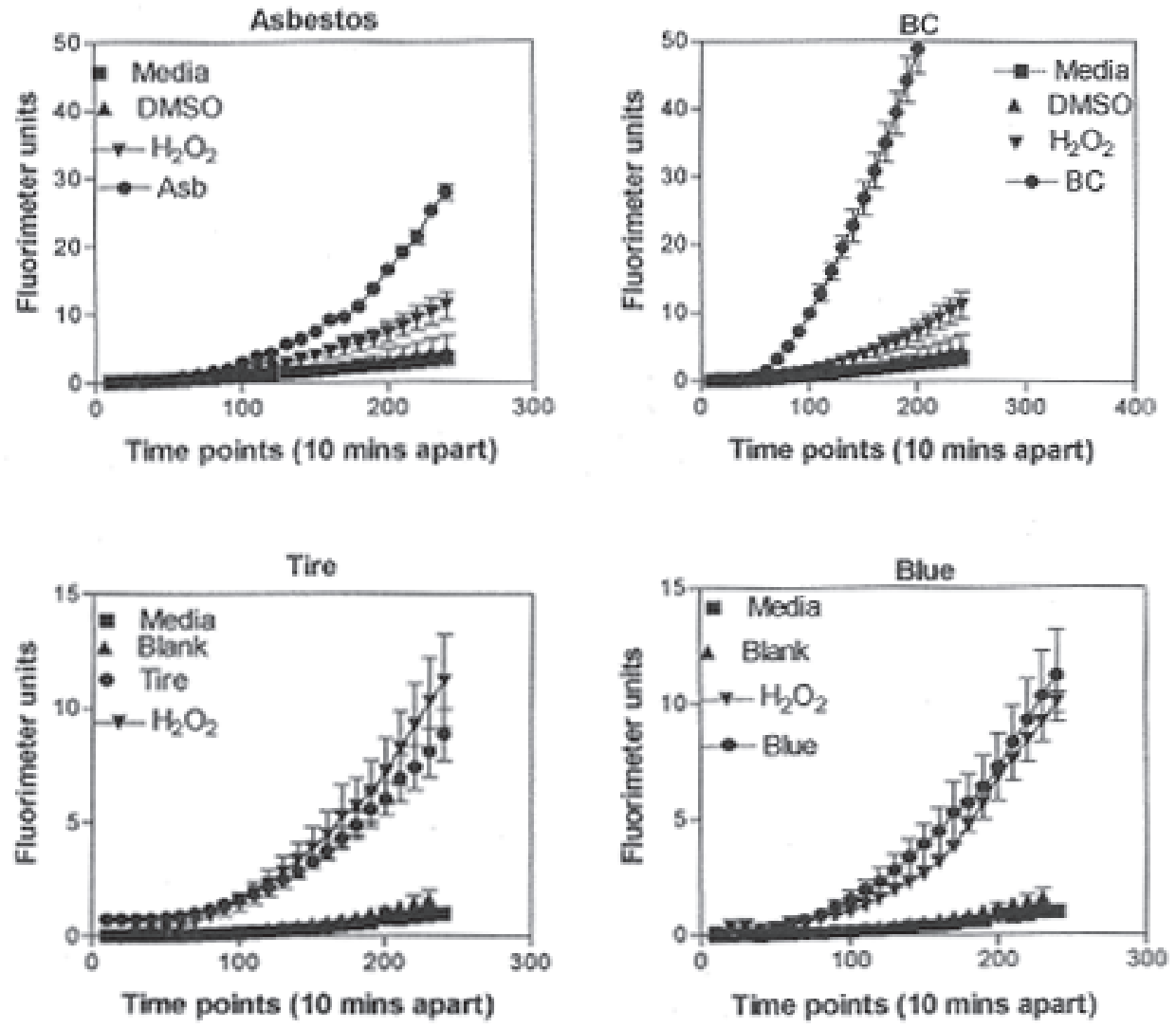

Figure 7 Examples of ROS generation of A549 cells. Media-treated cells and $\mathrm{H}_{2} \mathrm{O}_{2}$-treated cells were used as negative and positive controls, respectively and DMSO-treated cells functioned as a vehicle control. Presence of ROS was determined by the relative increase in fluorescence over time as shown. From Soto and colleagues (2008). Data are presented as the mean \pm SEM of quadruplicate wells and are one of three representative experiments. 


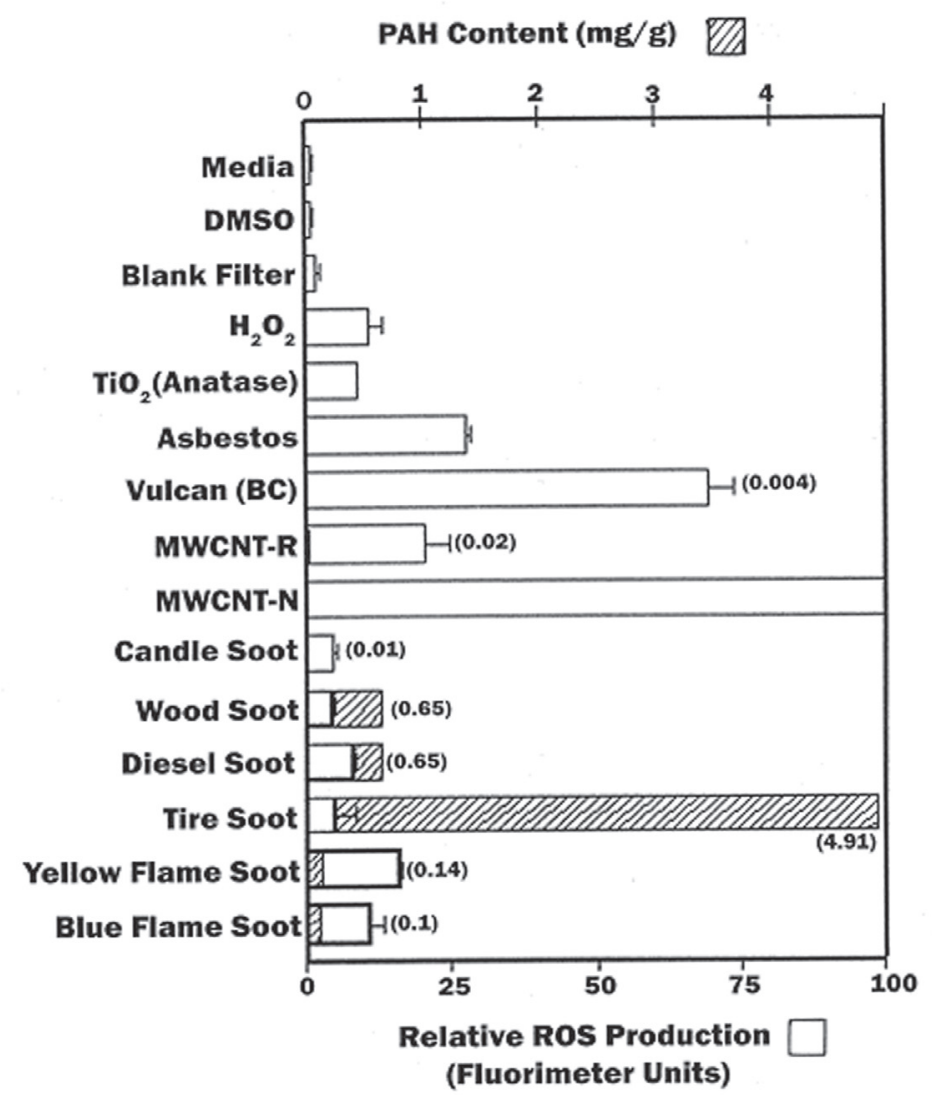

Figure 8 Summary of ROS generation and some corresponding total PAH content (data from Shi and colleagues (2007)) as cross-hatched and concentration noted in parentheses. Open bars show ROS generation by A549 cells 240 minutes after the addition of the DCA-DF dye following a $48 \mathrm{~h}$ treatment (incubation of cells with particulate matter). ROS data are presented as the mean \pm SEM of quadruplicate representative experiments, after Soto and colleagues (2008).

possible mechanisms by which nanomaterials interact with biological tissue, discontinuous crystal planes generating active electronic configurations, and this would appear to be the dominant issue for primary soot nanoparticles which are composed of curved graphene fragments intercalated with PAH isomers. But since PAH concentrations are not correlated with cytotoxic response (Figure 8), this leaves graphene fragment edges as potential sites for the

Table I PAH content of aggregated carbon and carbonaceous nano-PM ${ }^{* \dagger}$

\begin{tabular}{|c|c|c|c|c|c|c|c|c|c|}
\hline PAH & MW & BC & MWCNT-R & YNGPM & BNGPM & CPM & WPM & DPM & TPM \\
\hline Naphthalene & 128 & & $x$ & & & $x$ & & & $x$ \\
\hline Acenapthylene & 152 & & $x$ & & & & & & $x$ \\
\hline Acenapthene & 154 & & & & & & & & \\
\hline Fluorene & 166 & & $x$ & & & & & $x$ & $x$ \\
\hline Anthracene & 178 & & $\mathrm{X}$ & & & & $\mathrm{X}$ & $\mathrm{X}$ & $\mathrm{x}$ \\
\hline Phenanthrene & 178 & $x$ & $x$ & $\mathrm{x}$ & $x$ & & $x$ & $x$ & $x$ \\
\hline Fluoranthene & 202 & & & $\mathrm{x}$ & $x$ & & $x$ & $x$ & $x$ \\
\hline Pyrene & 202 & $\mathrm{X}$ & $X$ & $x$ & $x$ & & $x$ & $x$ & $x$ \\
\hline Chrysene & 228 & & & & & & $x$ & $x$ & $x$ \\
\hline Benz[a]anthracene & 228 & & & & $\mathrm{x}$ & & $x$ & & $x$ \\
\hline Benzo[b]fluoranthene & 252 & & & & & & $x$ & $\mathrm{x}$ & $x$ \\
\hline Benzo[k]fluoranthene & 252 & & & & & & $x$ & & $\mathrm{x}$ \\
\hline Benzo[a]pyrene & 252 & & & & & & $x$ & & $x$ \\
\hline Indeno[I,2,3-cd]pyrene & 276 & & & & & & $x$ & $\mathrm{X}$ & $x$ \\
\hline Benzo[g,h,i]phenylene & 276 & & & & & & $x$ & $x$ & $x$ \\
\hline
\end{tabular}

Notes: * $>$ I\% of total PAH content represented by $\mathrm{X}$; ${ }^{\dagger}$ Based on data in Shi and colleagues (2007).

Abbreviations: BC, black carbon; MWCNT-R, commercial arc-grown;YNGPM, yellow flame natural gas particulate matter; BNGPM, blue flame natural gas particulate matter; CPM, candle particulate matter; WPM, wood particulate matter; DPM, diesel particulate matter;TPM, tire particulate matter. 
Table 2 Summary of PAH concentration in indoor air (as percent of total)

\begin{tabular}{lccc}
\hline PAH & MW & S.E. Chicago* & El Paso $^{\dagger}$ \\
\hline Naphthalene & 128 & 79 & 92 \\
Acenapthylene & 152 & $\mathrm{I}$ & $\mathrm{I}$ \\
Acenapthene & 154 & 7 & $<\mathrm{I}$ \\
Fluorene & 166 & 6 & $\mathrm{I}$ \\
Anthracene & 178 & $<\mathrm{I}$ & 3 \\
Phenanthrene & 178 & 6 & 2 \\
Fluoranthene & 202 & -- & -- \\
Pyrene & 202 & $<\mathrm{I}$ & $<\mathrm{I}$ \\
Chrysene & 228 & -- & -- \\
Benz[a]anthracene & 228 & -- & -- \\
Benzo[b]fluoranthene & 252 & -- & -- \\
Benzo[k]fluoranthene & 252 & -- & -- \\
Benzo[a]pyrene & 252 & -- & -- \\
Indeno[I,2,3-cd]pyrene & 276 & -- & -- \\
\hline
\end{tabular}

Notes: *After data of Van Winkle and Scheff (2001); ${ }^{\dagger}$ After data of Mora and colleauges (2006).

generation of active electronic configurations which promote proinflammatory responses, cytokine release, and ROS production. Certainly this is speculative in terms of specific supporting data outside that provided in Figures 8 and 9, but this prospect may provide for avenues for future research directed more specifically at elucidating a more specific mechanism for nanoparticle and nanoparticle aggregate production of ROS from cell exposure.

\section{Summary and conclusions}

Cytotoxicity (in vitro) assays using immortalized, human cancer cells (A549) have shown positive responses (cell death) for a range of soot nanoparticle aggregates from burning candles, wood, diesel combustion tire burning, natural gas combustion, black carbon (BC), and commercial, arc-evaporation-produced MWCNTs; in order of increasing cell death (or decreasing cell viability) over a $48 \mathrm{~h}$ incubation period. Chrysotile asbestos nanotubes exhibited a response similar to natural gas combustion nano-PM, and the commercial MWCNT material.

All of the nanoparticulate soot aggregates were observed to be very similar in structure: turbostratic curved graphene fragments (with pentagonal curvature-inducing elements) variously intercalated with PAH isomeric fragments forming primary spherules ranging in diameter from 20-80 nm; forming branched, fractal-like aggregates. These aggregates were more open for tire soot and more dense for other soot aggregates. The aggregates contained from $<10^{2}$ to $>10^{3}$ primary spherules.

In vitro assays indicated significant ROS production for the chrysotile asbestos, $\mathrm{BC}$, and the commercial, catalytically produced MWCNT aggregate PM; with some noticeable ROS production for the natural gas nano-PM. While other soot PM produced ROS, it was below the $\mathrm{H}_{2} \mathrm{O}_{2}$ reference. There was no observed correlation of ROS production and

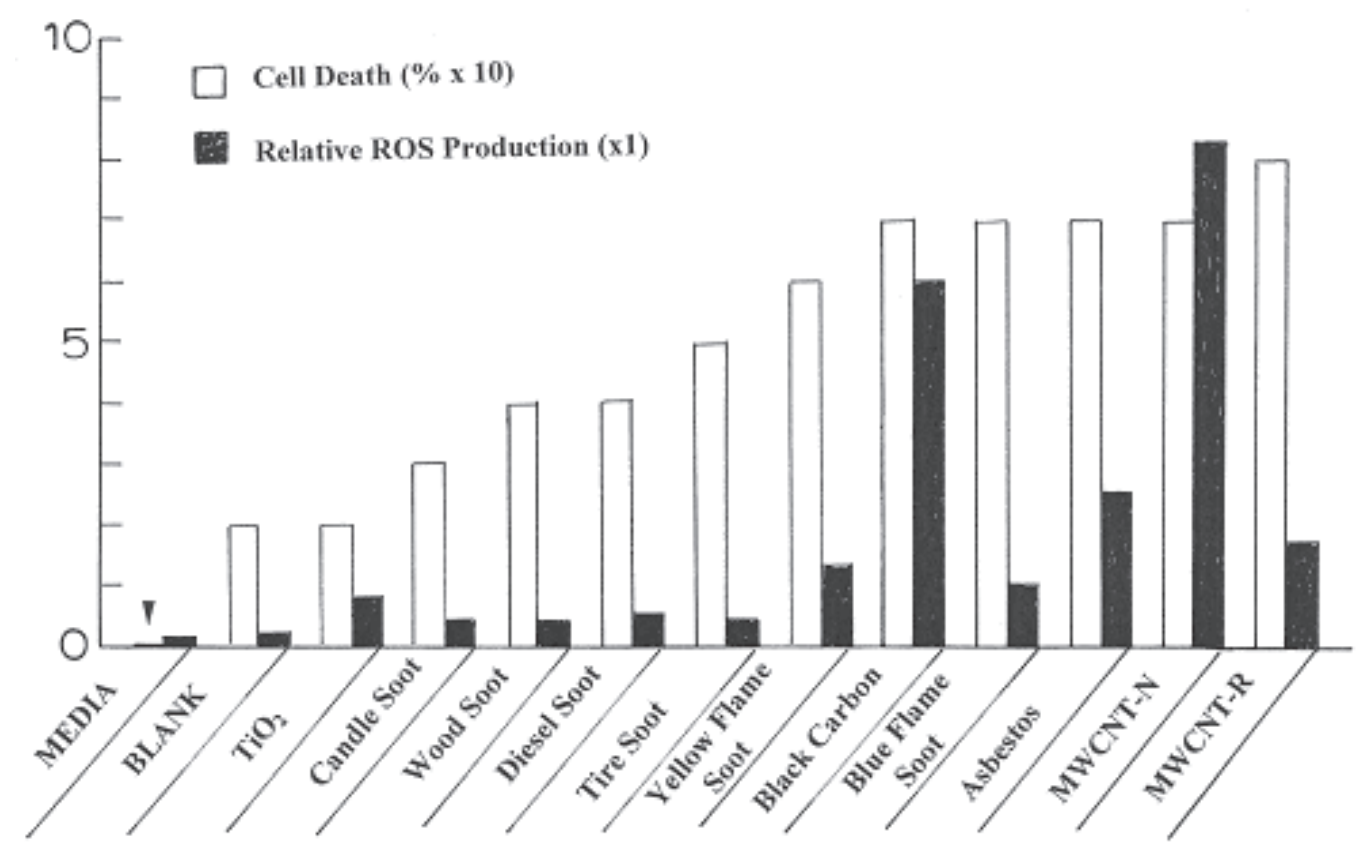

Figure 9 Comparison of cell death (percent) and relative ROS production for the nanoparticulate materials studied in this research program. The arrow at left is indicative of the media cell death reference at zero. 
total PAH content for any of the soot PM. This is an indication that while soot PM (including BC) is cytotoxic and produces ROS, neither is related to PAH content (Murr et al 2007); suggesting that carbon and carbonaceous nano-PM induce oxidative stress at various levels. There was at least a qualitative correlation between cell death and ROS production, suggesting that cell viability (cytotoxicity) assays can be indicative of ROS production.

\section{Acknowledgments}

This research was supported by the National Institute of Environmental Health Sciences (NIEHS)-NIH under grant number ISIIE5013339-01A1-Pilot Project 5. This research was also supported in part by the Southwest Consortion for Environmental Research and Policy (SCERP), Project A-05-01, and by an EPA Air and Radiation Scholarship (KFS). The contents of this paper are solely the responsibility of the authors and do not necessarily represent the official view of NIEHS, NIH, SCERP, or EPA.

\section{References}

Bell AT. 2003. The impact of nanoscience on heterogeneous catalysis. Science, 299:1688-92.

Bang JJ, Trillo EA, Murr LE. 2003. Utilization of selected area electron diffraction patterns for characterization of air submicron particulate matter collected by a thermal precipitator. $J$ Air and Waste Manag Assoc, 53:227-36.

Chalupa DC, Morrow PE, Oberdörster G, et al. 2004. Ultrafine particle deposition in subjects with asthma. Environ Health Perspect, 112:879-82.

Dahl A, Ghariba A, Swieflicki E, et al. 2006. Traffic-generated emissions of ultrafine particles from pavement - tire interface. Atmos Environ, 71:1314-23.

D’Amato G, Liccordi G. 1998. Outdoor environmental injury of the airways and development of allergic respiratory diseases. Pulmon Pharmacol Ther, 11:369-74.

Donaldson K, Stone V, Clouter A, et al. 2001. Ultrafine particles. Occup Environ Med, 58:211-15.

Donaldson K, Tran CL. 2002. Inflammation caused by particles and fibers. Trans Inhal Toxicol, 14:5-27.

Donaldson K, Stone V, Tran CL, et al. 2004. Nanotoxicology. Occup Environ Med, 61:727-35.

Englert N. 2004. Fine particles and human health - a review of epidemiological studies. Toxicol Lef, 149:235-42.

Frampton MW. 2001. Systemic and cardiovascular effects of airway injury and inflammation: ultrafine particle exposure in humans. Environ Health Perspectives, 109(Suppl. 40):529-32.

Gauderman WJ, Avol E, Gilliland F, et al. 2004. The effect of air pollution on lung development from 10 to 18 years of age. $N$ Engl $J$ Med, 351:1057-67.

Geller MD, Sioutas C, Fokkens PHB, et al. 2002. A methodology for measuring size-dependent chemical composition of ultrafine particles. Aerosol Sci Technol, 36:748-55.

Gwinn MR, Vallyathan V. 2006. Nanoparticles: Health effects - pros and cons. Environ Health Perspect, 114:1818-25.

Hellawell B, Gutteridge JMC. 1999. Free radicals in biology and medicine. Oxford: Oxford Univ Pr.

Homann K-H. 1998. Fullerenes and soot formation-New pathways to large particles in flames. Angew Chem Int Ed, 37:2434-51.
Johnson Jr. RL. 2004. Relative effects of air pollution on lungs and heart. Circulation, 109:5-7.

Kim, JJ, Smorodinsky S, Lipsett M, et al. 2004. Traffic-related pollution near busy roads: The East Bay Childrens Respiratory Health Study. Am J Respir Crit Care Med, 170:520-6.

Koenig JQ, Mar TF, Allen RW, et al. 2005. Pulmonary effects of indoor- and outdoor-generated particles in children with asthma. Environ Health Perspect, 113:499-503.

Lam C-W, James JT, McCloskey R, et al. 2006. A review of carbon nanotubes toxicity and assessment of potential occupational and environmental health risks. Crit Rev Toxicol, 36:189-217.

Lighty JS, Veranth JM, Sarofim AF. 2000. Combustion aerosols. Factors governing their size and composition and implications for human health. J Air and Waste Manage Assoc, 50:1565-618.

Mora J, Gamez J, Astorga-Bustillo F, et al. 2006. Speciation of indoor air pollutants and associated inhalation health hazards caused by cooking and heating in Hispanic households, Report to Southwest Consortium for Environmental Research and Policy (SCERP), June 30.

Murr LE. 1991. Electron and ion nicroscopy and microanalysis: Principles and applications. New York: Marcel Dekker, Inc.

Murr LE, Bang JJ. 2003. Electron microscopy comparisons of fine and ultrafine carbonaceous and nano-carbonaceous, airborne particulates. Atmos Environ, 37:4795-806.

Murr LE, Bang JJ, Esquivel EA, et al. 2004. Carbon nanotubes, nanocrystal forms, and complex nanoparticle aggregates in common fuel gas combustion streams. J Nanoparticle Res, 6:241-51.

Murr LE, Guerrero PA. 2006. Carbon nanotubes in wood soot. Atmos Sci Lett, 7:93-5.

Murr LE, Soto KF. 2004. A TEM comparison of chrysotile (asbestos) nanotubes and carbon nanotubes. J Mater Sci, 39:4941-7.

Murr LE, Soto KF, Garza KM, et al. 2006. Combustion-generated nanoparticulates in the El Paso, TX, USA/Juarez, Mexico metroplex: Their comparative characterization and potential for adverse health effects. Int J Environ Res and Public Health, 3:48-66.

Murr LE, Soto KF, Garza KM. 2007. Health hazards of manufactured, natural environmental and other anthropogenic atmospheric nanoparticulate materials: past, present and future. In: Oechsner A, et al. (eds). Biomaterials and Biomedical Engineering. Trans Tech Publishers, Switzerland, pp. 1-54.

Nel A. 2005. Atmosphere. Air-pollution-related illness: effects of particles. Science, 308(5723):804-6.

Nel A, Xia T, Madler L, et al. 2006. Toxic potential of materials at the nanolevel. Science, 311(5761):622-7.

Oberdörster G. 2001. Pulmonary effects of inhaled ultrafine particles. Int Arch Occup Environ Health, 74:1-8.

Oberdörster G, Oberdörster E, Oberdörster J. 2005. Nanotechnology: an energizing discipline evolving from studies of ultrafine particles. Environ Health Perspect, 113:823-9.

O'Neili MS, Veves A, Zanobetti A, et al. 2005. Diabetes enhances vulnerability to particulate air pollution-associated impairment in vascular reactivity and endothelial function. Circulation, 111:2913-20.

Peters A, Dockery DW, Heinrich J, et al. 1997. Short-term effects of particulate air pollution on respiratory morbidity in asthmatic children. Eur RespirJ, 10:872-9.

Pietropaoli AP, Frampton MW, Hyde RW, et al. 2004. Pulmonary function, diffusing capacity, and inflammation in healthy and asthmatic subjects exposed to ultrafine particles. Inhal Toxicol, 16(Suppl. 1):59-72.

Pope III CA, Burnett RT, Thurston GD, et al. 2004. Cardiovascular mortality and long-term exposure to particulate air pollution: epidemiological evidence of general pathophysiological pathways of disease. Circulation, 109:71-7.

Pope III CA, Dockery DW. 2006. Health effects of fine particulate air pollution: Lines that connect. J Air and Waste Manage Assoc, 56:709-42.

Pope III CA, Thon MJ, Namboodiri MM, et al. 1995. Particulate air pollution as a predictor of mortality in a perspective study of U.S. adults. Am J Respir Crit Care Med, 151(part 1):669-74. 
Samet JM, Dominici F, Curriero FC, et al. 2000. Fine particulate air pollution and mortality in 20 U.S. cities, 1987-1994. $N$ Engl J Med, 343:161-6.

Shi Y, Murr LE, Soto KF, et al. 2007. Characterization and comparison of speciated atmospheric carbonaceous (soot) particulates and their polycyclic aromatic hydrocarbon contents in the context of the Paso del Norte airshed along the U.S.-Mexico border. Polycyclic Aromatic Comp, 27:361-400.

Shvedova AA, Kisin ER, Mercer R, et al. 2005. Unusual inflammatory and fibrogenic pulmonary responses to single-walled carbon nanotubes in mice. Am J Physiol, 289:L698-L705.

Soto KF, Carrasco A, Powell TG, et al. 2005. Comparative in vitro cytotoxicity assessment of some manufactured nanoparticulate materials characterized by transmission electron microscopy. $J$ Nanoparticle Res, 7:145-69.

Soto KF, Carrasco A, Powell TG, et al. 2006. Biological effects of nanoparticulate materials. Mater Sci Engng, 26:1421-7.

Soto KF, Garza KM, Murr LE. 2007. Cytotoxic effects of aggregated nanomaterials. Acta Biomaterialia, 3:351-8.
Soto KF, Murr LE, Garza KM. 2008. Cytotoxic responses and potential respiratory health effects of carbon and carbonaceous nanoparticulates in the Paso del Norte airshed environment. Int J Environ Res and Public Health, In press.

Vander Wal RL, Tomasek AJ. 2004. Soot nanostructure: Dependence upon synthesis conditions. Combust and Flame, 136:129-40.

Van Winkle MR, Scheff PA. 2001. Volatile organic compounds, polycyclic aromatic hydrocarbons, and elements in the air of ten urban homes. Indoor Air, 11:49-64.

Veronesi B, deHaar C, Lee L, et al. 2002. The surface charge of visible particulate matter predicts biological activation in human bronchial epithelial cells. Toxicol Appl Pharmacol, 178:144-54.

Violi A, Venkatnathan A. 2006. Combustion-generated nanoparticles produced in a benzene flame: a multiscale approach. J Chem Phys, 125(5):054302.

Warheit DB. 2004. Nanoparticles health effects? Mater Today, 32-5.

Warheit DB, Webb TR, Sayes CM, et al. 2006. Pulmonary instillation studies with $\mathrm{TiO}_{2}$ rods and dots in rats: toxicity is not dependent upon particle size and surface area. Toxicol Sci, 91(1):227-36. 